\title{
The Association between Preschool Children's Social Functioning and Their Emergent Academic Skills
}

\author{
David H. Arnold, \\ Psychology Department, University of Massachusetts, Amherst \\ Janis B. Kupersmidt, \\ FPG Child Development Institute, University of North Carolina, Chapel Hill \\ Mary Ellen Voegler-Lee, and \\ FPG Child Development Institute, University of North Carolina, Chapel Hill \\ Nastassja Marshall \\ University of Massachusetts, Amherst
}

\begin{abstract}
This study examined the relationship between social functioning and emergent academic development in a sample of 467 preschool children $(M=55.9$ months old, $S D=3.8)$. Teachers reported on children's aggression, attention problems, and prosocial skills. Preliteracy, language, and early mathematics skills were assessed with standardized tests. Better social functioning was associated with stronger academic development. Attention problems were related to poorer academic development controlling for aggression and social skills, pointing to the importance of attention in these relations. Children's social skills were related to academic development controlling for attention and aggression problems, consistent with models suggesting that children's social strengths and difficulties are independently related to their academic development. Support was not found for the hypothesis that these relationships would be stronger in boys than in girls. Some relationships were stronger in African American than Caucasian children. Children's self-reported feelings about school moderated several relationships, consistent with the idea that positive feelings about school may be a protective factor against co-occurring academic and social problems.
\end{abstract}

\section{Keywords}

preschool; academic development; social development; behavior problems

\begin{abstract}
The importance of children's social functioning to their academic progress has been increasingly recognized (Duncan et al., 2007). Dynamic, ecological models that include broad contextual and child influences on early child achievement have informed recent research (Rimm-Kaufman \& Pianta, 2000) and guide the present study. The accompanying empirical research literature on the intersection between social and academic development
\end{abstract}

\footnotetext{
(C) 2012 Elsevier Inc. All rights reserved.

Correspondence concerning this article should be addressed to David Arnold, Psychology Department, Tobin Hall, University of Massachusetts, Amherst, MA 01003. darnold@psych.umass.edu. Phone: 413-545-2157. Fax: 413-545-0996.

Publisher's Disclaimer: This is a PDF file of an unedited manuscript that has been accepted for publication. As a service to our customers we are providing this early version of the manuscript. The manuscript will undergo copyediting, typesetting, and review of the resulting proof before it is published in its final citable form. Please note that during the production process errors may be discovered which could affect the content, and all legal disclaimers that apply to the journal pertain.
} 
has grown, clearly establishing that social functioning is critical to school readiness (Huffman, Mehlinger, \& Kerivan, 2000). In particular, research suggests that children's attention problems, aggression, and prosocial behaviors are important to consider in understanding the social context that may interfere with or facilitate learning. However, significant gaps remain in understanding these connections (Arnold \& Doctoroff, 2003); more remains to be learned about the interplay among these constructs, particularly in their emergent stages.

Numerous studies with children in elementary school and beyond link behavior problems to academic difficulties, using a wide range of measures of both behavior problems and academic achievement (Duncan et al., 2007; Heller, Baker, Henker, \& Hinshaw, 1996; Hinshaw, 1992a, 1992b). Research further suggests that, in understanding behavior problems in this relationship, it is important to separate aggression from attention difficulties (e.g., Arnold, 1997; Lonigan et al., 1999). Prosocial behavior, defined as positive social behaviors that enable effective interactions with others, including cooperation, responsibility, and empathy (Gresham \& Elliot, 1990; Malecki \& Elliott, 2002), appears to be another developmental domain that is important to consider in models of academic development (Dobbs, Doctoroff, Fisher, \& Arnold, 2006; Malecki \& Elliot, 2002; Welsh, Parke, Widaman, \& O'Neil, 2001). Based on this previous work, the present study focuses on a) attention difficulties, b) aggression, and c) prosocial behaviors as three aspects of children's social functioning that are relevant to academic development. More research is needed to illuminate the intersection of academic development with these components of social functioning, especially in preschool children. The current study builds on previous research by examining how all three of these aspects of social functioning are related to preliteracy, language, and mathematics development in a high-risk, low-SES sample of preschoolers, and further extends the literature by considering gender, ethnicity, and feelings about school as possible moderators of relations between these constructs.

\section{A Model of the Interplay between Social Functioning and Academic Development}

The literature suggests a model of reciprocal associations between social functioning and academic skills in which problems in either area can lead to difficulties in the other (e.g., Trzesniewski, Moffitt, Caspi, Taylor, \& Maughan, 2006). In this model, attention difficulties may play a key role in the onset and escalation of these problems (Arnold, 1997;

Dominiquez Escalón \& Greenfield, 2009; Duncan et al., 2007; Finn, Pannozzo, \& Voelkl, 1995; Hinshaw, 1992b; Lonigan et al., 1999; McWayne \& Cheung, 2009; Normandeau \& Guay, 1998), with aggression playing an increasingly important role as children get older. More specifically, it is thought that attention difficulties limit children's ability to engage in learning activities, benefit from instruction, and focus on educational tasks. Academic difficulties, in turn, may eventually lead to increased frustration, lower engagement and poorer self-esteem, in time leading to aggression that will further interfere with learning. Prosocial behaviors, on the other hand, may serve as a protective factor against these problems, by increasing a teacher's investment in a child, facilitating persistence, and in turn fostering decreased frustration and better learning. More empirical data are needed to evaluate this model, particularly in the emergent stages of academic development. Next, we review and critique the literature with respect to each of the social functioning components of this model, with an emphasis on the state of knowledge at the preschool age.

\section{Attention problems}

It appears clear that attention is related to early academic development. Arnold (1997) found that observed attention problems in diverse, low-SES preschoolers were related to both 
language and preliteracy development. Dobbs et al. (2006) found that, of the 11 scales on the Teacher Report Form, attention problems were the strongest predictor of mathematics development in a sample of Head Start children. Lonigan et al. (1999) also found that teacher-rated attention problems were related to a wide range of emergent literacy skills in both low-SES and middle-income preschoolers. Friedman-Weieneth, Harvey, Youngwirth, and Goldstein (2007) showed that both teacher- and parent-rated attention difficulties were associated with poorer scores on a composite measure of preacademic skills in a sample of preschoolers with clinically significant behavior problems. These studies provide support for the idea that attention problems may be central to emergent academic development.

\section{Aggression}

The relationship between aggression and academic development in preschoolers is less clear. Aggression is clearly associated with academic development in older children (Hinshaw, 1992a, 1992b), but it may be less important in preschoolers. Dobbs et al. (2006) found that teacher-rated aggression was not a significant predictor of mathematics development in Head Start children. Friedman-Weieneth et al. (2007) found that neither teacher nor parent ratings of aggression were significantly associated with 3-year-old children's preacademic skills. On the other hand, some studies have found associations between aggression and emergent academic development. For example, Stevenson, Richman, and Graham (1985) found that parent-reported undifferentiated behavior problems, which included aggression, were related to poorer language development in a community sample, and Kaiser, Cai, Hancock, and Foster (2002) showed that teacher externalizing ratings (a composite of measure of behavior problems that included aggression) predicted language development in Head Start children. Doctoroff, Greer, and Arnold (2006) found that observed aggressive behaviors predicted emergent literacy in mostly low-SES preschool boys. However, it is possible that these associations could be accounted for by co-occurring attention difficulties. Arnold (1997) found a relationship between observed problem behaviors and academic development in low-SES preschoolers, but it was largely accounted for by attention difficulties. Lonigan et al. (1999) found a similar pattern in which teacher ratings of aggression were related to preacademic development, but not once attention problems were controlled for, and they found this same pattern in both a middle-income and a low-income sample of preschoolers.

\section{Prosocial behavior}

Finally, much less research has examined the relationship between prosocial skills and academic development in preschool, but those suggest that positive social functioning is related to emergent academic development. Doctoroff et al. (2006) found a relationship between observed prosocial skills and emergent academic development in preschool boys. Dobbs et al. (2006) found that teacher-rated prosocial skills predicted mathematics development in Head Start. However, too little is known about whether these associations represents a unique relationship between prosocial behavior and academic development, or whether they might be accounted for by other aspects of social development.

\section{Areas in Need of Further Attention}

The present study does not provide a full test of the above model of reciprocal associations between social functioning and academic skills, but is designed as a step toward improving knowledge about the model, in a population at risk because of low-SES. This cross-sectional study aims to add to theory by a) better differentiating aspects of social functioning and academic development; b) making progress with respect to measurement and analyses; and c) adding to knowledge about possible moderators of these relationships. 


\section{Differentiation of social functioning}

The above model and extant data suggest that it is important to better distinguish among aspects of social functioning (Dobbs et al., 2006; Giannopulu, Escolano, Cusin, Citeau, \& Dellatolas, 2008; Morgan, Farkas, Tufis, \& Sperling, 2008). La Paro and Pianta (2000) reviewed the literature on school readiness assessments; they found that social functioning is widely considered a critical component of school readiness, but they point to the need for empirical evaluation of this construct, stating that" efforts to conceptualize and measure those processes... will require considerable attention" (p. 476). Many previous studies have considered undistinguished behavior problems (Hinshaw, 1992b). Better differentiation of social functioning is needed to help better understand how specific behaviors relate to academic development. In particular, distinctions should be made between aggression and attention difficulties, given preliminary evidence that attention problems may be particularly disruptive to academic development. Further, children's strengths as well as weaknesses should be considered, given theory and some evidence that social skills facilitate academic development (Bramlett, Scott, \& Rowell, 2000; Dobbs et al., 2006; Doctoroff et al., 2006; Martin, 1994), particularly in the early stages of academic development (Miles \& Stipek, 2006). Studies considering social functioning have usually not controlled for other aspects of this construct - the bivariate correlations typically presented may be misleading given the interrelations between components of social development. In sum, more data are needed to establish which aspects of social functioning are independently related to academic development (see, for example, Dobbs et al., 2006; Doctoroff et al., 2006).

\section{Differentiation of academic development}

More comprehensive measures of academic development are also needed. To our knowledge, no one study of social and academic development in preschoolers has included measures of early language, preliteracy, and mathematics achievement. Most studies with young children have focused on language or preliteracy skills, but early mathematics development should be included, given its particularly strong relationship with later achievement (Duncan et al., 2007), and evidence that developmental influences may differ for reading and mathematics achievement (e,g., Pungello, Kupersmidt, Burchinal, \& Patterson, 1996). A few studies have examined the relation between social functioning and mathematics development in preschoolers, and those suggest a link between them (Dobbs et al., 2006; Dominquez Escalón \& Greenfield, 2009; Fantuzzo et al., 2007; Hindman, Skibbe, Miller, \& Zimmerman, 2010).

\section{Measurement and analytic considerations}

Many studies of preschoolers have relied on teacher report of both academic development and social functioning (e.g., Kaiser et al., 2002). These were very important studies, but resulted in shared method variance; objective measures of academic development are needed to avoid inflated estimates of their relationships (Kazdin, 1998; Hinshaw, 1992b). In addition, studies have typically not taken into account the nesting of children within classrooms; having one teacher report on multiple children violates assumptions of independent error, but the recent accessibility of Hierarchical Linear Modeling (HLM) allows this issue to be addressed (Raudenbush \& Bryk, 2002).

\section{The need to examine moderators}

The model presented above does not include moderators of the relationships, because so little work has been done in this area. Analyses that identify individual differences in these relations would further help in understanding factors that protect or place children at risk for this serious combination of problems. Identifying moderators requires substantial power, so perhaps it is not surprising that little has been done regarding interactions in these 
associations. There have been multiple calls for research on moderating variables (e.g., Dobbs et al., 2006; Hinshaw, 1992b; McWayne \& Cheung, 2009), but few such data have been presented. The current study takes a step in this direction, by focusing on three such possible moderators: gender, ethnicity, and children's feelings about school.

Gender-Gender has been examined in a few studies of the relation between social functioning and preschool academic development in economically disadvantaged children; some of these findings suggest that these relations may be stronger for boys than girls (Doctoroff et al., 2006; Kaiser et al., 2002; Stowe, Arnold, \& Ortiz, 1999; Trzesniewski et al., 2006). These differences in relationships have been linked to an "invisible girl" phenomenon in which girls' academic problems are likely to go unnoticed and unaddressed (Stowe et al., 1999) because of fewer accompanying disruptive behaviors. On the other hand, some studies have not found moderating effects of gender (e.g., Duncan et al., 2007). Establishing whether gender moderates the relationship between social functioning and academic development in low-SES preschoolers is important toward evaluating whether models of academic development need to account for gender differences, and toward evaluating whether interventions might need to be targeted or adjusted to differing mechanisms.

Ethnicity-Ethnicity as a possible moderator of these relationships in preschoolers has not, to our knowledge, been examined. One study of first graders found that attention problems predicted academic achievement less strongly in Latino than Caucasian or African American students, though no explanation for this pattern was offered (Rabiner, Murray, Schmid, \& Malone, 2004). Despite the lack of literature directly on this topic, ethnicity has commonly emerged as a moderator in other areas of educational research, including, for example, early teaching practices (Stipek, 2004), student-teacher relationships (den Brok, van Tartwijk, Wubbels, \& Veldman, 2010), and motivational influences (McDonald, Ing, \& Marcoulides, 2010). This work does not provide the basis for specific predictions in the current study, but does suggest that it should not be assumed that similar relationships hold across diverse groups. Calls have been made for cultural contexts to be considered (e.g., Forehand \& Kotchick, 1996), and examining ethnicity as a possible moderator of relationships between academic development and social functioning would provide one step toward such understanding.

Feelings about school-Children's feelings about school might also be an important moderator of relationships between social functioning and academic development, given the importance of children's interest, motivation, and engagement to their academic development. Theory points to disengagement from school as a possible reason for a worsening cycle between social and academic difficulties (Singh, Granville, \& Dika, 2002), suggesting that children with positive feelings about school may be less academically impacted by problems in social functioning. Their engagement in school may, for example, make teachers more likely to invest effort into addressing difficulties, and/or make their efforts more likely to succeed. Positive feelings about school may also be associated with persistence, which may be particularly important in the face of social difficulties (Schoen \& Nagle, 1994). Extant research is consistent with this notion, in establishing a clear relation between feelings about school and achievement (Valeski \& Stipek, 2001), and a negative relationship between disengagement and achievement (Fantuzzo et al., 2007). However, feelings about school have not been examined as a moderator of the relation between academic development and social functioning in preschoolers. 


\section{The Present Study}

The present study adds to the existing literature by including more differentiated assessments of both social functioning and academic development than most previous work; by including a large sample, which provides the power to examine gender, ethnicity, and feelings about school as possible moderators of relationships; and by conducting this examination in a high-risk sample of economically disadvantaged, diverse preschoolers. Ratings of aggression, attention problems, and social skills were obtained from teachers, while independent assessments of language, preliteracy, and mathematics were conducted. The relationships between these variables were examined, and Hierarchical Linear Modeling (HLM) was employed to account for the nesting of children within classrooms.

Relationships between social functioning and academic development were examined, including the extent to which various aspects of social functioning are related to academic development controlling for others. Gender was evaluated as a possible moderator of these relationships, with the prediction that these relationships would be weaker in girls than in boys. Ethnicity was also evaluated as a possible moderator of these relationships. Because of the lack of previous research on this topic, we did not have specific predictions about the direction of these possible interactions. Finally, children's feelings about school were examined as a hypothesized moderator of relations between social functioning and academic development, toward improving theory and possibly identifying a leverage point in interrupting negative cycling between academic and social difficulties.

\section{Method}

\section{Participants}

Participants were 467 children ( 242 boys) and their lead teachers from 84 classrooms at 44 different centers, as part of a larger study on preventing academic and externalizing difficulties (Baker, Kupersmidt, Voegler-Lee, Arnold, \& Willoughby, 2010; Kupersmidt et al., 2011). The study received University IRB approval and approval from the relevant center programs. Sixteen of these centers were Head Start centers; the rest were community child care centers that were demographically similar to the Head Start centers. Eligible classrooms were those comprised of at least 50\% 4-year-old children in the fall of the school year (October 15). Children averaged 55.9 months of age $(S D=3.8)$ at the time of the academic testing. Children's race/ethnicity, as described by parents, was: $58 \%$ African American, 29\% White, 4\% Hispanic, 1\% Asian, 6\% multi-racial, and 2\% other. Maternal education data were obtained for 300 of the children (some parents provided consent for their children to participate, but did not complete the demographic questionnaire); on average, their mothers had completed 13.3 years of education $(S D=2.3$; Median $=13)$.

\section{Measures}

Preliteracy-Three tests were administered to assess children's preliteracy development. Two were from the Woodcock-Johnson-III Tests of Achievement (Woodcock, McGrew, \& Mather, 2001) - the Letter-Word Identification and the Sound Awareness subtests. LetterWord Identification measures children's decoding skills, while Sound Awareness assesses children's phonetic knowledge. In the Letter-Word Identification, children are asked to name letters and read words. Example items include "D" "cat," "have," and "only." In Sound Awareness, children are asked to rhyme, delete, substitute, and reverse sounds. Example items include "Look at eye, pie, and sock. Show me two that end alike or rhyme," and "Say raincoat without saying rain." The reliability of these scales has been estimated for 4-year-olds as .98 and .71, respectively (McGrew, Schrank, \& Woodcock, 2007). Strong content and concurrent validity has been established, and evidence for construct equivalence across ethnic groups has been presented (Woodcock et al., 2001). In addition, the Story and 
Print Concepts (Administration on Children, Youth, and Families, 2003) was administered to assess children's knowledge about print. This test measures book knowledge, print knowledge, and story comprehension. Example items include "Where do I go next when I read?" and "Look at his face. How is Eddie feeling here?" This measure was used in the FACES Head Start study with diverse preschoolers. Reliability estimates for subscales range from .43 to .74 , with demonstrated predictive validity with respect to kindergarten literacy development (Administration on Children, Youth, and Families, 2003). Internal consistency (Cronbach's alpha) for this measure was .77 in the current sample.

A composite measure of preliteracy skills was created by averaging children's z-scores on these three measures (i.e., Letter-Word Identification, Sound Awareness, and Story and Print Concepts). Correlations among these three tests ranged from .31 to .35 (all $p s<.001$ ), and correlations of each test with the composite ranged from .73 to .75 (all $p \mathrm{~s}<.001$ ). The decision to create a composite measure was driven by a strong empirical literature suggesting that these variables together capture a range of preliteracy skills that are welllinked to future reading achievement (e.g., Whitehurst \& Lonigan, 1998). In addition, this data reduction reduces risk of Type I errors (Cohen, Cohen, West, \& Aiken, 2003). Results are substantively unchanged if these variables are considered separately.

Language-Children's receptive language skills were assessed with the Peabody Picture Vocabulary Test-III(PPVT-III, Dunn \& Dunn, 1997). Children are presented with a page of four pictures and asked to point to the picture that a word describes. Example words include "bus," "digging" and "shoulder." This widely-used test has shown high internal consistency, with an alpha of .95 for 4-year-old children (Williams \& Wang, 1997). Extensive studies demonstrate this measure's validity across diverse samples, including convergent validity with other language and cognitive measures, predictive validity with respect to later academic achievement, and the ability to distinguish clinical language difficulties (Dunn \& Dunn, 1997). Standard scores (i.e., nationally normed to have a mean of $100, S D=15$ ) are reported.

Mathematics-The Applied Problems subscale of the Woodcock-Johnson-III was administered to assess children's mathematics skills. Example items include "How many apples are there?" and "If I took one car away, how many would be left?" This subscale has high reliability, with an internal consistency estimate of .94 from previous studies (Woodcock et al., 2001), and well-demonstrated validity with respect to content and concurrent validity, as well as predictive validity in terms of later academic achievement and the ability to identify significant mathematics achievement difficulties (Woodcock et al., 2001). Evidence for construct equivalence across ethnic groups has also been presented (Woodcock et al., 2001). Standard scores (i.e., mean $=100, S D=15$ ) are reported.

Feelings about school-Children reported on their feelings about school with an assessment based closely on the Feelings about School (FAS) measure developed by Stipek and colleagues (Valeski \& Stipek, 2001). Children were taught to indicate how much they like different things with two practice items: getting a present and getting in trouble. Children learned to point at one of five faces that ranged from having big frowns to big smiles. They then indicated how much they liked various school activities and school in general across seven items. Example items include "How much do you like numbers?", and "How much do you like school?" This approach has been used with preschoolers in previous studies with reliability estimates of .62 and .73 (Arnold, Fisher, Doctoroff, \& Dobbs, 2002; Stipek \& Ryan, 1997), and validity data are available across young children of various ethnic groups (Arnold et al., 2002; Stipek \& Ryan, 1997; Valeski \& Stipek, 2001). FAS scores were sensitive to intervention effects in a diverse Head Start sample of 4-year-olds, with changes corresponding to those found with teacher report (Arnold et al., 2002). They 
were also significantly related to teacher ratings of academic skills in a diverse sample of kindergarteners (Valeski \& Stipek, 2001). In a sample of diverse, disadvantaged 4-year-olds, FAS scores were related to later achievement, controlling for initial status (Stipek \& Ryan, 1997). Internal consistency in the current sample was .69. Responses were scored from 1-5 and average scores ranging from 1 to 5 are reported.

Attention problems-Children's attention difficulties were assessed by teachers' reports on the attention problems subscale of the IOWA Conners Teacher Rating Scale. Teachers rate children from 0 (not at all) to 3 (very much) on five items that assess attention and overactivity problems. Example items include "Fails to finish things he or she starts (short attention span)," "inattentive, easily distracted," and "excitable, impulsive." Pelham, Milich, Murphy, and Murphy (1989) presented normative data for this scale on a sample of 608 older children, with internal consistency of .89. Internal consistency for this form version has not been reported with preschoolers, but similar versions have reported internal consistency upwards of .87 with preschoolers (McGoey, DuPaul, Haley, \& Shelton, 2007). Internal consistency in the current sample was .81. There are strong validity data on this widely-used scale (e.g., Casat, Norton, \& Boyle-Whitesel, 1999; Nolan \& Gadow, 1994; Pelham et al., 1989), and findings suggest that construct equivalence applies across children from different ethnic groups (Reid, Casat, Norton, Anastopoulos, \& Temple, 2001). Raw scores, potentially ranging from 0 to 15 , are reported.

Aggression-The IOWA Conners Teacher Rating Scale (Pelham et al., 1989) was also used to assess aggression. Teachers rate children from 0 (not at all) to 3 (very much) on five items that assess aggressive behavior. Example items include "quarrelsome," "defiant," and "uncooperative." Internal consistency for this five-item scale has been reported as .92 for older children (Pelham et al., 1989). Internal consistency for this form version has not been reported with preschoolers, but similar versions have reported internal consistency upwards of .87 with preschoolers (McGoey et al., 2007). Internal consistency in the current sample was .86. Findings suggest that construct equivalence applies across children from different ethnic groups (Reid et al., 2001). Raw scores, potentially ranging from 0 to 15 , are reported.

Social skills-Teachers completed the Social Skills Rating System (SSRS), a 30-item assessment of children's prosocial skills, such as cooperation, assertion, and self-control, on 3-point scales ranging from 0 (never) to 2 (very often) (Gresham \& Elliott, 1990). Example items include "Follows directions," and "Volunteers to help peers." Internal consistency has been estimated at .88 for elementary school students (Gresham \& Elliott, 1990) and as high as .95 for preschoolers (Rich, Shepherd, \& Nangle, 2008). Internal consistency in the current sample was .87. Validity data supporting this scale are extensive, and include samples of diverse preschool children (e.g., Demaray et al., 1995; Flanagan, Alfonso, Primavera, Povall, \& Higgins, 1996; Rich et al., 2008). Standard scores (i.e., mean $=100, S D=15$ ) based on normative samples are reported.

\section{Procedure}

All parents of 4-year-olds in participating classrooms were sent a letter that described the study and invited their participation. Children whose parents provided consent were included in the present study, with a participation rate of 50.3\% percent of the invited parents. Complete comparisons between participating and non-participating children cannot be made (e.g., language and mathematics tests were not administered to children without parent consent), so it cannot be concluded with certainty that participating children were representative of their centers. However, it seems likely that they are at least fairly similar, based on some teacher ratings that were made for all children. Specifically, participating and non-participating children did not significantly differ on teacher ratings of attention or 
aggression. In addition, participating and non-participating children did not significantly differ with respect to age or gender. Participating children did differ with respect to ethnicity $(p<.01)$, with participating children more likely to be Caucasian than in the larger sample ( $16 \%$ of the children in the full sample were Caucasian).

Teachers filled out ratings of each child, and were paid $\$ 15$ for their time. Child academic assessments were conducted by trained project staff in a private setting at the child's center. These assessments were conducted in a single session of approximately 30-45 minutes; all measures in the current study were collected concurrently in the fall (i.e., this is a crosssectional study). Children were given a book and stickers for participating.

\section{Results \\ Descriptive Statistics}

Table 1 presents the means and standard deviations of the central study variables, for the whole sample and by gender. Of the 467 participating children, rates of missing data were low: measures were completed for $97 \%-100 \%$ of participating children for the central variables (see Table 1). Within each analysis, casewise deletion was used for handling these few missing data. Aggression showed moderate skew (skew index $=1.4$ ); untransformed analyses are presented for ease of communication and comparison to previous studies, but analyses conducted with a successful square root transformation showed substantively identical findings. Girls and boys differed on several of these variables. With respect to emergent academic skills, girls scored significantly higher than boys on the Letter-Word and Sound Awareness assessments, though these effect sizes were small ( $d$ s of .23 and .26, respectively). With respect to social functioning, boys scored higher on teacher ratings of inattention and aggression, but also on ratings of social skills. These differences on social functioning variables were larger than the differences in academic development ( $d$ s ranged from .39 to .46), but still below Cohen's threshold for a medium-sized effect. Boys showed significantly greater variability than did girls on ratings of inattention and aggression, while girls showed greater variability in social skills ratings.

\section{Relationships between Academic Development and Social Functioning}

Table 2 presents the intercorrelations between the main variables of this study. Bivariate correlations were used to examine the relation between each social predictor (inattention, aggression, and social skills) and each academic outcome (preliteracy, language, and mathematics). In the interest of interpretability and comparability to previous studies, these correlations are standard Pearson correlations that do not account for the nesting of children within classrooms. Though not presented, when these simple relationships were estimated using HLM to account for nesting, relationships tended to be slightly stronger, but not substantially different. The correlations between social functioning and academic development were all in the predicted direction, and were significantly related in the majority of cases (six out of nine); however, the strength of these relations was modest. Although the direct relationship between feelings about school and academic development was not the focus of this paper, the strength of the relations between these constructs is striking.

\section{Independence of Predictors}

These analyses were conducted using HLM (version 6.0; Raudenbush, Bryk, \& Congdon, 2004), to account for children's nesting within classrooms. Even though the assessments and study questions are at the level of the individual child, teachers report on multiple children, violating the regression assumption of independence of error. HLM allows for unbiased estimates in this situation (Raudenbush \& Bryk, 2002). Before running our hierarchical 
models, we first calculated intraclass correlation coefficients (ICCs) to quantify the extent to which children within a classroom were similar with respect to their academic development (Hox, 1995; Kreft \& de Leeuw, 1998). These ICCs were .17, .31, and .20 for the preliteracy, language, and mathematics measures, respectively. Examination of variability across classrooms (i.e., level two random effects) revealed that, not surprisingly, achievement scores significantly varied across classrooms on all three measures. However, with respect to the relationships between social functioning and academic development, the only relationship that showed significant variability across classrooms was the relationship between SSRS and preliteracy skills [variance component $(41)=.07, \chi^{2}=68.16, p=.005$ ]. This relation was thus allowed to vary as a random effect while other relationships were constrained as fixed effects (Ma, Ma, \& Bradley, 2008).

Each of the academic variables was regressed on inattention, aggression, and social skills scores, with gender included as a control variable (i.e., three separate models were estimated), to evaluate each independent variable's relationship, controlling for the others. All variables except for gender, which remained dichotomous, were transformed to z-scores before conducting these analyses, so the resulting weights for these analyses can be interpreted as standardized weights (i.e., the $S D$ change in Y associated with a $1 S D$ change in the predictor, controlling for the other predictors). An example of one of our two-level random intercepts mixed linear model, predicting language scores is:

$$
\text { Language }=\gamma_{00}+\gamma_{10}{ }^{*} \text { Gender }_{\mathrm{ij}}+\gamma_{20}{ }^{*} \text { Inattention }_{\mathrm{ij}}+\gamma_{30}{ }^{*} \text { Agression }_{\mathrm{ij}}+\gamma_{40}{ }^{*} \text { Social Skills }_{\mathrm{ij}}+u_{0 \mathrm{j}}+r_{\mathrm{ij}}
$$

We allowed the relationship between social skills and preliteracy to vary across classrooms as a random effect, as described above, so the relevant model for that analysis is:

Preliteracy $=\gamma_{00}+\gamma_{10}{ }^{*}$ Gender $_{\mathrm{ij}}+\gamma_{20}{ }^{*}$ Inattention $_{\mathrm{ij}}+\gamma_{30}{ }^{*}$ Agression $_{\mathrm{ij}}+\gamma_{40}{ }^{*}$ Social Skills $_{\mathrm{ij}}+u_{0 \mathrm{j}}+u_{4 j}{ }^{*}$ Social Skills $r_{\mathrm{ij}}$.

Resulting weights are presented in Table 3. Attention problems were associated with both lower preliteracy and lower language scores, controlling for aggression and social skills. Aggression was not significantly related to any academic measures when controlling for these other variables. Social skills were significantly related to each academic outcome, controlling for inattention and aggression.

\section{Gender as a Moderator}

Possible moderators were examined by regressing each academic outcome, in turn, onto one social predictor, the predicted moderator, and an interaction term (a multiplicative term created from these two variables). These analyses again utilized HLM to account for the nesting of children within classrooms. We predicted that relationships between social and academic variables would be stronger in boys than in girls. Because there were three academic outcome variables and three social variables, nine regression analyses were conducted; contrary to predictions, gender did not significantly moderate any of these relationships (all interaction $p s>.05$ ). On the other hand, the overall pattern of results was generally consistent with the prediction that relationships would be stronger for boys -- of the nine correlations between social and academic variables, seven were stronger for boys than for girls. This pattern provides very limited support for the possibility of slightly stronger relations among boys than girls. Table 4 illustrates this pattern with the un-nested correlations; the pattern is the same for correlations calculated using HLM. 


\section{Ethnicity as a Moderator}

Given the dearth of previous research examining whether these relationships differ as a function of ethnicity, we conducted exploratory analyses evaluating whether ethnicity moderated the relationships between social functioning and academic development. Only African American and Caucasian children were included in these analyses given the small number of participants of other ethnicities. Three of the relationships between social and academic development were significantly moderated by ethnicity; in each case, the relationship was stronger for African American children. Specifically, ethnicity moderated the relationship between attention problems and mathematics development (interaction $B=$ $-.17, S E=.08, p=.04$ ), between aggression and preliteracy development (interaction $B=-$. 22, $S E=.10, p=.03$ ), and between aggression and mathematics development (interaction $B$ $=-.16, S E=.08, p=.05$ ). Correlations among the study variables for these two groups are presented in Table 5 to illustrate these differences. The proportion of unexplained variance accounted for by the interactions, relative to the same model without the interaction term, was less than 4 percent in each of the three cases.

\section{Feelings about School as a Moderator}

Feelings about school moderated the relationships between aggression and academic functioning, such that the strength of the relations was attenuated when feelings about school were more positive. See Figure 1 for an example of these interactions. Specifically, children's feelings about school moderated the relationship between aggression and language scores (interaction $B=.10, S E=.04, p=.01$ ), and between aggression and mathematics development (interaction $B=.09, S E=.04, p=.02$ ), such that the relations were weaker for children with more positive feelings about school. The interaction between FAS and aggression in predicting preliteracy scores was in the predicted direction but was not significant (interaction $B=.07, S E=.04, p=.07$ ). Finally, the interaction between FAS scores and inattention in predicting mathematics was also in the predicted direction but was not significant (interaction $B=.07, S E=.04, p=.09$ ). The proportion of unexplained variance accounted for by the interactions, relative to the same model without the interaction term, was less than 5.3 percent in each case.

\section{Discussion}

The current study found a number of significant relationships between social functioning and academic development, providing support for the idea that these relationships begin prior to formal schooling. The fact that academic and social development are related at an early age suggests the hopeful possibility that early intervention programs that benefit one area might have positive effects on the other.

Attention difficulties were related to emergent academic development controlling for aggression and prosocial behavior, consistent with previous literature suggesting that attention may play a central role in these relations, and with theory suggesting that attention difficulties could directly interfere with learning (Friedman-Weieneth et al., 2007; Lonigan et al., 1999). Children's social skills were related to emergent academic development, controlling for attention and aggression problems. The finding that children's strengths were independently related to achievement is consistent with theory and prior research suggesting that positive behaviors are important in their own right, rather than simply as the absence of negatives (Dobbs et al., 2006). We expect that prosocial behaviors might be helpful in maintaining positive relationships with teachers in the face of frustrations; these relationships have been shown to be an important predictor of achievement (Crosnoe et al., 2010). Aggression was only weakly related to preliteracy development, and was not a unique predictor when other social variables were included. This finding is consistent with 
other work with preschoolers (Friedman-Weieneth et al., 2007; Lonigan et al., 1999), but research with grade-school children suggests that aggression becomes a more important predictor of achievement as children grow older (e.g., Miles \& Stipek, 2006). It is possible that in the context of increased academic expectations of later grades, aggression interferes with academic progress as a consequence of frustration, decreased learning opportunities, and accompanying poor academic performance, creating a negative cycle in which acting out and achievement problems feed on each other. However, research is needed to untangle the processes of these relations as they unfold across time.

The relationships between social and academic variables in the present study were significant but small, in absolute terms and compared to previous studies. Results may be an accurate estimation of the relationship strengths, given the multiple influences on early academic development. It is also possible that results are somewhat attenuated by the reliance on teacher report of social functioning. The current academic assessments represent a methodological improvement over studies that have relied on teacher report for both academic and behavioral measures, but multiple sources of information about children's social functioning might yield stronger results by including the information offered by observations and parent report (Kazdin, 1998). Finally, this study took into account the hierarchical structure of children nested within classrooms, and this could be responsible for some of the result differences.

The present study included social skills, which is a step forward, but future research should extend this work with more comprehensive measures of this construct. Prosocial behavior is a complex and multifaceted construct (Eisenberg, Vaughan, \& Hofer, 2009; Fantuzzo, Bulotsky-Shearer, Fusco, \& McWayne, 2005); future work should evaluate which components of social skills predict academic development. Future studies should also include internalizing problems as a predictor of early academic development, which has been little studied in preschoolers (for an exception see Bub, McCartney, \& Willett, 2007), given that work with older children points to its importance (e.g., Moilanen, Shaw, \& Maxwell, 2010).

Contrary to hypotheses, we did not find evidence that gender significantly moderated the relationships between academic development and social functioning, though in most cases findings were in the expected direction. The lack of significant interactions is in contrast to several previous studies that suggested girls' academic problems are less visible than boys because they are less connected to behavior problems (Stowe et al., 1999). On the other hand, some previous studies also found no gender moderation (Duncan et al., 2007). Although it is difficult to interpret non-significant findings, it is worth noting that they are unlikely to be an artifact of low power - the sample size of the present project is much larger than in most previous studies. The reasons for the discrepancies in findings across studies are not clear, and questions about gender differences remain open.

Ethnicity significantly interacted with social functioning in predicting academic development in three of the relationships. In each case, relationships were stronger for African American than Caucasian children. We do not have the data that would be needed to determine the reasons for this pattern, and frankly we are unsure why this pattern emerged. Children's behavior was measured with teacher-report, so influences on teachers' perceptions certainly might be relevant (Hamre, Pianta, Downer, \& Mashburn, 2008; Mashburn, Downer, Hamre, \& Pianta, 2006), though we are not clear why these influences would lead to differential relationships with academic development. It is possible that teachers may react to social problems in African American children with more conflict, and such conflict could interfere with academic support (Stipek \& Miles, 2008). Another possible explanation is that African American parents whose children exhibit strong 
academic development might respond with especially strong support, perhaps toward countering negative stereotypes, thus supporting social development. Alternatively, even though all of the families in the current study were low-SES, the African American families might be hit especially hard by poverty, given that they face the additional difficulties associated with societal prejudice and stereotypes, thus causing difficulties in multiple areas of children's development. These explanations remain speculative until further studies replicate and illuminate this pattern.

Children's feelings about school moderated several of the relationships between social functioning and academic development as predicted, such that social and academic development were less strongly associated in children with more positive feelings about school. It is expected that positive feelings about school help maintain engagement in the face of frustrations, consistent with research on the importance of academic interest, motivation, and engagement in general (Dominquez Escalón \& Greenfield, 2009; Eccles, Wigfield, \& Schiefele, 1998; McWayne \& Cheung, 2009), and of children's feelings about school in particular (Valeski \& Stipek, 2001). The results also point to the importance of including these constructs in comprehensive models of academic development, and suggest that disaffection with school may be important to consider and address even in the earliest education stages. The findings regarding feelings about school should be interpreted with caution given the scale's reliability (alpha $=.69$ ), though reliability problems typically attenuate results rather than create Type I error.

The current results support and extend theory in several ways. They extend evidence that social and academic development are interconnected from early in development, using a large sample and independent information sources. They add to the body of work pointing toward attention difficulties as central in the early stages of these relationships (Arnold, 1997; Lonigan et al., 1999). Findings show that these connections include prosocial skills on the social front, and mathematics on the academic front. The interaction analyses add to theory by identifying two moderators of these relationships, and pointing to feelings about school as an important factor in the relations. The interaction results also suggest the importance of further research on individual differences in these relationships. With regard to gender, this study raises more questions than it answers in an already divided literature, pointing to the need for continued consideration of this area. Overall, findings align with and extend previous theory on the relationships between these constructs, and add support to La Paro and Pianta's (2000) conclusion that the concept of school readiness badly needs additional empirical attention.

Limitations of this study include the correlational nature of the design, which precludes causal conclusions. Because only half of invited parents participated, caution is warranted in generalizing these findings, even with respect to other low-income samples. In addition, the present study provides only a first step toward understanding moderators and mechanisms in these relationships. More studies are needed that examine processes and individual differences in these relationships. The present study did not examine mediators of the observed relationships, which will be helpful in identifying intervention points to address these problems. Longitudinal data, which will eventually be provided by the current project, will also allow better understanding of how these constructs unfold across time. More dynamic and comprehensive models, for example using structural equation approaches, should be evaluated. These efforts could be complemented with experimental studies to help to determine causality and in these relationships, while also providing applied benefits toward breaking negative cycles between social and academic difficulties. For example, if an intervention that targets and reduces behavior problems (e.g., Raver et al., 2009) also resulted in academic gains, this would provide clues as to causal relations. 
The practice and policy implications of these findings are preliminary but exciting. With respect to assessment screenings, they point to the importance of including attention difficulties and social skills. The connections between social and academic development suggest that broader interventions including prosocial components may help address the risk of academic failure. Finally, the finding that positive feelings about school may be a protective factor provides an additional possible leverage point in disrupting the serious risks associated with co-occurring social and academic difficulties.

\section{Acknowledgments}

This project was supported by grant R01HD046126 (Kupersmidt), co-funded by the National Institute of Child Health and Human Development (NICHD), the Administration for Children and Families (ACF), the Office of the Assistant Secretary for Planning and Evaluation (ASPE), and the Office of Special Education and Rehabilitative Services (OSERS) in the U.S. Education Department.

\section{References}

Administration on Children, Youth and Families. Head Start FACES 2000: A whole child perspective on program performance (Fourth progress report). Washington, DC: U.S. Department of Health and Human Services; 2003.

Arnold DH. Co-occurrence of externalizing behavior problems and emergent academic difficulties in high-risk boys: A preliminary evaluation of patterns and mechanisms. Journal of Applied Developmental Psychology. 1997; 18:317-330.10.1016/S0193-3973(97)80003-2

Arnold DH, Doctoroff GL. Early education of socioeconomically disadvantaged children. Annual Review of Psychology. 2003; 54:517-545. doi:0.1146/annurev.psych.54.111301.145442.

Arnold DH, Fisher PH, Doctoroff GL, Dobbs J. Accelerating mathematics development in Head Start classrooms. Journal of Educational Psychology. 2002; 94:762-770.10. 1037/0022-0663.94.4.762

Baker CN, Kupersmidt JB, Voegler-Lee ME, Arnold DH, Willoughby MT. Teacher participation in a classroom-based, multi-dimensional preventive intervention for preschoolers. Early Childhood Research Quarterly. 2010; 25:270-283.10.1016/j.ecresq.2009.09.005 [PubMed: 21103189]

Bramlett RK, Scott P, Rowell RK. A comparison of temperament and social skills in predicting academic performance in first graders. Special Services in the Schools. 2000; 16:147-158.10.1300/ J008v16n01

Bub KL, McCartney K, Willett JB. Behavior problem trajectories and first-grade cognitive ability and achievement skills: A latent growth curve analysis. Journal of Educational Psychology. 2007; 99:653-670.10.1037/0022-0663.99.3.653

Casat CD, Norton HJ, Boyle-Whitesel M. Identification of elementary school children at risk for disruptive behavioral disturbance: Validation of a combined screening method. Journal of the American Academy of Child and Adolescent Psychiatry. 1999; 38:12461253.10.1097/00004583-200011000-00003 [PubMed: 10517057]

Cohen, J.; Cohen, P.; West, SG.; Aiken, LS. Applied multiple regression/correlation for the behavioral science. 3. Mahwah, NJ: Erlbaum; 2003.

Crosnoe R, Morrison F, Burchinal M, Pianta R, Keating D, Friedman SL, Clarke-Stewart AK. Instruction, teacher-student relations, and mathematics achievement trajectories in elementary school. Journal of Educational Psychology. 2010; 102:407-417.10.1037/a0017762 [PubMed: 20657743]

den Brok P, van Tartwijk J, Wubbels T, Veldman I. The differential effect of the teacher-student interpersonal relationship on student outcomes for students with different ethnic backgrounds. British Journal of Educational Psychology. 2010; 80:199-221. doi:0.1348/000709909X465632. [PubMed: 19619406]

Demaray MK, Ruffalo SL, Carlson J, Busse RT, Olson AE, McManus S, Leventhal A. Social skills assessment: A comparative evaluation of six published rating scales. School Psychology Review. $1995 ; 24: 648-671$. 
Dobbs J, Doctoroff GL, Fisher PH, Arnold DH. The association between preschool children's socioemotional functioning and their mathematical skills. Journal of Applied Developmental Psychology. 2006; 27:97-108.10.1016/j.appdev.2005.12.008

Doctoroff GL, Greer J, Arnold DH. The relationship between social behavior and emergent literacy in preschool boys and girls. Journal of Applied Developmental Psychology. 2006; 27:1-13.10.1016/ j.appdev.2005.12.003

Dominiquez Escalón X, Greenfield DB. Learning behaviors mediating the relationship between behavior problems and academic outcomes. NHSA Dialog. 2009; 12:117.10.1080/15240750802590768

Duncan GJ, Dowsett CJ, Claessens A, Magnuson K, Huston A, Klebanov P, Japel C. School readiness and later achievement. Developmental Psychology. 2007; 43:14281446.10.1037/0012-1649.43.6.1428 [PubMed: 18020822]

Dunn, LM.; Dunn, LM. Peabody Picture Vocabulary Test. 3. Circle Pines, MN: American Guidance Services; 1997. (PPVT-III)

Eccles, J.; Wigfield, A.; Schiefele, U. Motivation to succeed. In: Damon, W.; Eisenberg, N., editors. Handbook of child psychology: Vol. 3. Social, emotional, and personality development. 5. New York, NY: Wiley; 1998. p. 1017-1095.

Eisenberg, N.; Vaughan, J.; Hofer, C. Temperament, self-regulation, and peer social competence. In: Rubin, KH.; Bukowski, WM.; Laursen, B., editors. Handbook of peer interactions, relationships, and groups. New York, NY: Guilford Press; 2009. p. 473-489.

Fantuzzo J, Bulotsky-Shearer R, McDermott PA, McWayne C, Frye D, Perlman S. Investigation of dimensions of social-emotional classroom behavior and school readiness for low-income urban preschool children. School Psychology Review. 2007; 36:44-62.

Fantuzzo JW, Bulotsky-Shearer R, Fusco RA, McWayne C. An investigation of preschool classroom behavioral adjustment problems and social-emotional school readiness competencies. Early Childhood Research Quarterly. 2005; 20:259-275.10.1016/j.ecresq.2005.07.001

Finn JD, Pannozzo GM, Voelkl KE. Disruptive and inattentive-withdrawn behavior and achievement among fourth graders. Elementary School Journal. 1995; 95:421-434.10.1086/461853

Flanagan DP, Alfonso VC, Primavera LH, Povall L, Higgins D. Convergent validity of the BASC and SSRS: Implications for social skills assessment. Psychology in the Schools. 1996; 33:1321.10.1002/(SICI)1520-6807(199601)33:1<13::AID-PITS2>3.0.CO;2-X

Forehand R, Kotchick BA. Cultural diversity: A wake-up call for parent training. Behavior Therapy. 1996; 27:187-206.10.1016/S0005-7894(96)80014-1

Friedman-Weieneth JL, Harvey EA, Youngwirth SD, Goldstein LH. The relation between 3-year-old children's skills and their hyperactivity, inattention, and aggression. Journal of Educational Psychology. 2007; 99:671-681.10.1037/0022-0663.99.3.671

Giannopulu I, Escolano S, Cusin F, Citeau H, Dellatolas G. Teachers' reporting of behavioural and cognitive-academic performances in children aged 5-7 years. British Journal of Educational Psychology. 2008; 78:127-147.10.1348/00070907X204372 [PubMed: 17535517]

Gresham, FM.; Elliott, SN. Social Skills Rating System manual. Circle Pines, MN: American Guidance Service; 1990.

Hamre BK, Pianta RC, Downer JT, Mashburn AJ. Teachers' perceptions of conflict with young students: Looking beyond problem behaviors. Social Development. 2008; 17:115-136.

Heller TL, Baker BL, Henker B, Hinshaw SP. Externalizing behavior and cognitive functioning from preschool to first grade: Stability and predictors. Journal of Clinical Child Psychology. 1996; 25:376-387.

Hindman AH, Skibbe LE, Miller A, Zimmerman M. Ecological contexts and early learning: Contributions of child, family, and classroom factors during Head Start, to literacy and mathematics growth through first grade. Early Childhood Research Quarterly. 2010; 25:235250.10.1016/j.ecresq.2009.11.003

Hinshaw SP. Academic underachievement, attention deficits, and aggression: Comorbidity and implications for intervention. Journal of Consulting and Clinical Psychology. 1992a; 60:893903.10.1037/0022-006X.60.6.893 [PubMed: 1460150] 
Hinshaw SP. Externalizing behavior problems and academic underachievement in childhood and adolescence: Causal relationships and underlying mechanisms. Psychological Bulletin. 1992b; 111:127-155.10.1037/0033-2909.111.1.127 [PubMed: 1539086]

Hox, J. Applied multilevel analysis. Amsterdam, Netherlands: TT-Publikaties; 1995.

Huffman, LC.; Mehlinger, SL.; Kerivan, AS. Off to a good start: Research on the risk factors for early school problems. Chapel Hill, NC: University of North Carolina FPG Child Development Center; 2000.

Kaiser AP, Cai X, Hancock TB, Foster EM. Teacher-reported behavior problems and language delays in boys and girls enrolled in Head Start. Behavioral Disorders. 2002; 28:23-39.

Kazdin, AE. Research design in clinical psychology. Boston, MA: Allyn and Bacon; 1998.

Kreft, I.; de Leeuw, J. Introducing multilevel modeling. Thousand Oaks, CA: Sage; 1998.

Kupersmidt, JB.; Voegler-Lee, ME.; Arnold, DH.; Willoughby, M.; Field, S.; Bryant, D.; PeisnerFeinberg, E. Professional development and curriculum enhancements for behavioral and academic kindergarten readiness: The Building Bridges program. 2011. Manuscript submitted for publication

La Paro KM, Pianta RC. Predicting children's competence in the early school years: A meta-analytic review. Review of Educational Research. 2000; 70:443-484.10.3102/00346543070004443

Lonigan CJ, Bloomfield BG, Anthony JL, Bacon KD, Phillips BM, Samwel CS. Relations among emergent literacy skills, behavior problems, and social competence in preschool children from low- and middle-income backgrounds. Topics in Early Childhood Special Education. 1999; 62:4053.10.1177/027112149901900104

Ma, X.; Ma, L.; Bradley, KD. Using multilevel modeling to investigate school effects. In: O'Connell, AA.; McCoach, DB., editors. Multilevel modeling of educational data. Charlotte, NC: Information Age Publishing; 2008. p. 59-119.

Malecki C, Elliot SN. Children's social behaviors as predictors of academic achievement: A longitudinal analysis. School Psychology Quarterly. 2002; 17:1-23.10.1521/scpq.17.1.1.19902

Martin RP. Child temperament and common problems in schooling: Hypotheses about causal connections. Journal of School Psychology. 1994; 32:119-134.10.1016/0022-4405(94)90006-X

Mashburn AJ, Hamre BK, Downer JT, Pianta RC. Teacher and classroom characteristics associated with teachers' ratings of prekindergarteners' relationships and behaviors. Journal of Psychoeducational Assessment. 2006; 24:367-380.10.1177/0734282906290594

McDonald SR, Ing M, Marcoulides GA. An investigation of early parental motivational strategies on mathematics achievement by ethnicity: A latent curve model approach. Educational Research and Evaluation. 2010; 16:401-419. doi:0.1080/13803611.2010.530447.

McGoey KE, DuPaul GJ, Haley E, Shelton TL. Parent and teacher ratings of attention-deficit/ hyperactivity disorder in preschool: The ADHD rating scale-IV preschool version. Journal of Psychopathology and Behavioral Assessment. 2007; 29:269-276.10.1007/s10862-007-9048-y

McGrew, KS.; Schrank, FA.; Woodcock, RW. Woodcock-Johnson III normative update. Rolling Meadows, IL: Riverside Publishing; 2007. Technical manual.

McWayne CM, Cheung C. A picture of strength: Preschool competencies mediate the effects of early behavior problems on later academic and social adjustment for Head Start children. Journal of Applied Developmental Psychology. 2009; 30:273-285.10.1016/j.appdev.2008.12.014

Miles SB, Stipek D. Contemporaneous and longitudinal associations between social behavior and literacy achievement in a sample of low-income elementary school children. Child Development. 2006; 77:103-117.10.1111/j.1467-8624.2006.00859.x [PubMed: 16460528]

Moilanen KL, Shaw DS, Maxwell KL. Developmental cascades: Externalizing, internalizing, and academic competence from middle childhood to early adolescence. Development and Psychopathology. 2010; 22:635-653.10.1017/S0954579410000337 [PubMed: 20576184]

Morgan PL, Farkas G, Tufis PA, Sperling RA. Are reading and behavior problems risk factors for each other? Journal of Learning Disabilities. 2008; 41:417-436.10.1177/0022219408321123 [PubMed: 18768774]

Nolan EE, Gadow KD. Relation between ratings and observations of stimulant drug response in hyperactive children. Journal of Clinical Child Psychology. 1994; 23:78-90. 
Normandeau S, Guay F. Preschool behavior and first-grade school achievement: The meditational role of cognitive self-control. Journal of Educational Psychology. 1998; 90:111121.10.1037/0022-0663.90.1.111

Pelham EG, Milich R, Murphy DA, Murphy HA. Normative data on the Iowa Conners Teacher Rating Scale. Journal of Clinical Child Psychology. 1989; 18:259-262.

Pungello EP, Kupersmidt JB, Burchinal MR, Patterson CJ. Environmental risk factors and children's achievement from middle childhood to early adolescence. Developmental Psychology. 1996; 32:755-767.10.1037/0012-1649.32.4.755

Rabiner DL, Murray DW, Schmid L, Malone PS. An exploration of the relationship between ethnicity, attention problems, and academic achievement. School Psychology Review. 2004; 33:498-509.

Raudenbush, SW.; Bryk, AS. Hierarchical linear models: Applications and data analysis methods. Thousand Oaks, CA: Sage Publications; 2002.

Raudenbush, SW.; Bryk, AS.; Congdon, R. HLM 6 for Windows (Version 6.0) [computer software]. Lincolnwood, IL: Scientific Software International Inc; 2004.

Raver CC, Jones SM, Li-Grining C, Fuhua Z, Metzger MW, Solomon B. Targeting children's behavior problems in preschool classrooms: A cluster-randomized controlled trial. Journal of Consulting and Clinical Psychology. 2009; 77:302-316.10.1037/a0015302 [PubMed: 19309189]

Reid R, Casat CD, Norton HJ, Anastopoulos AD, Temple EP. Using behavior rating scales for ADHD across ethnic groups: The IOWA Conners. Journal of Emotional and Behavioral Disorders. 2001; 9:210-218.10.1177/106342660100900401

Rich EC, Shepherd EJ, Nangle DW. Validation of the SSRS-T, preschool level as a measure of positive social behavior and conduct problems. Education and Treatment of Children. 2008; 31:183-202.10.1353/etc.0.0026

Rimm-Kaufman SE, Pianta RC. An ecological perspective on the transition to kindergarten: A theoretical framework to guide empirical research. Journal of Applied Developmental Psychology. 2000; 21:491-511.10.1016/S0193-3973(00)00051-4

Schoen MJ, Nagle RJ. Prediction of school readiness from kindergarten temperament scores. Journal of School Psychology. 1994; 32:135-147.10.1016/0022-4405(94)90007-

Singh K, Granville M, Dika S. Mathematics and science achievement: Effects of motivation, interest, and academic engagement. Journal of Educational Research. 2002; 95:323332.10.1080/00220670209596607

Stevenson J, Richman N, Graham P. Behaviour problems and language abilities at three years and behavioral deviance at eight years. Journal of Child Psychology and Psychiatry. 1985; 26:215230.10.1111/j.1469-7610.1985.tb02261.x [PubMed: 3980611]

Stipek D. Teaching practices in kindergarten and first grade: Different strokes for different folks. Early Childhood Research Quarterly. 2004; 19:548-568.10.1016/j.ecresq.2004.10.010

Stipek DJ, Miles S. Effects of aggression on achievement: Does conflict with teachers make it worse? Child Development. 2008; 79:1721-1735.10.1111/j.1467-8624.2008.01221.x [PubMed: 19037945]

Stipek DJ, Ryan RH. Economically disadvantaged preschoolers: Ready to learn but further to go. Developmental Psychology. 1997; 33:711-723.10.1037/0012-1649.33.4.711 [PubMed: 9232386]

Stowe RM, Arnold DH, Ortiz C. Gender differences in the relation of language development to disruptive behavior and peer relationships in preschoolers. Journal of Applied Developmental Psychology. 1999; 20:521-536.10.1016/S0193-3973(99)00024-6

Trzesniewski KH, Moffitt TE, Caspi A, Taylor A, Maughan B. Revisiting the association between reading achievement and antisocial behavior: New evidence from an environmental explanation from a twin study. Child Development. 2006; 77:72-88.10.1111/j.1467-8624.2006.00857.x [PubMed: 16460526]

Valeski TN, Stipek DJ. Young children's feelings about school. Child Development. 2001; 72:11981213.10.1111/1467-8624.00342 [PubMed: 11480942]

Welsh M, Parke RD, Widaman K, O’Neil R. Linkages between children's social and academic competence: A longitudinal analysis. Journal of School Psychology. 2001; 39:463-482.10.1016/ S0022-4405(01)00084-X 
Whitehurst GJ, Lonigan CJ. Child development and emergent literacy. Child Development. 1998; 69:848-872.10.2307/1132208 [PubMed: 9680688]

Williams, KT.; Wang, J-J. Technical references to the Peabody Picture Vocabulary Test. 3. Circle Pines, MN: American Guidance Services; 1997. (PPVT-III)

Woodcock, RW.; McGrew, KS.; Mather, N. Woodcock-Johnson III Tests of Achievement. Itasca, IL: Riverside Publishing; 2001. 


\section{Research Highlights}

- Examined emergent academic development and social functioning in preschoolers.

- Attention problems predicted poorer academic development.

- Social skills predicted stronger academic development.

- Some relationships were stronger in African American than Caucasian children.

- Positive feelings about school moderated relationships and may be a protective factor. 


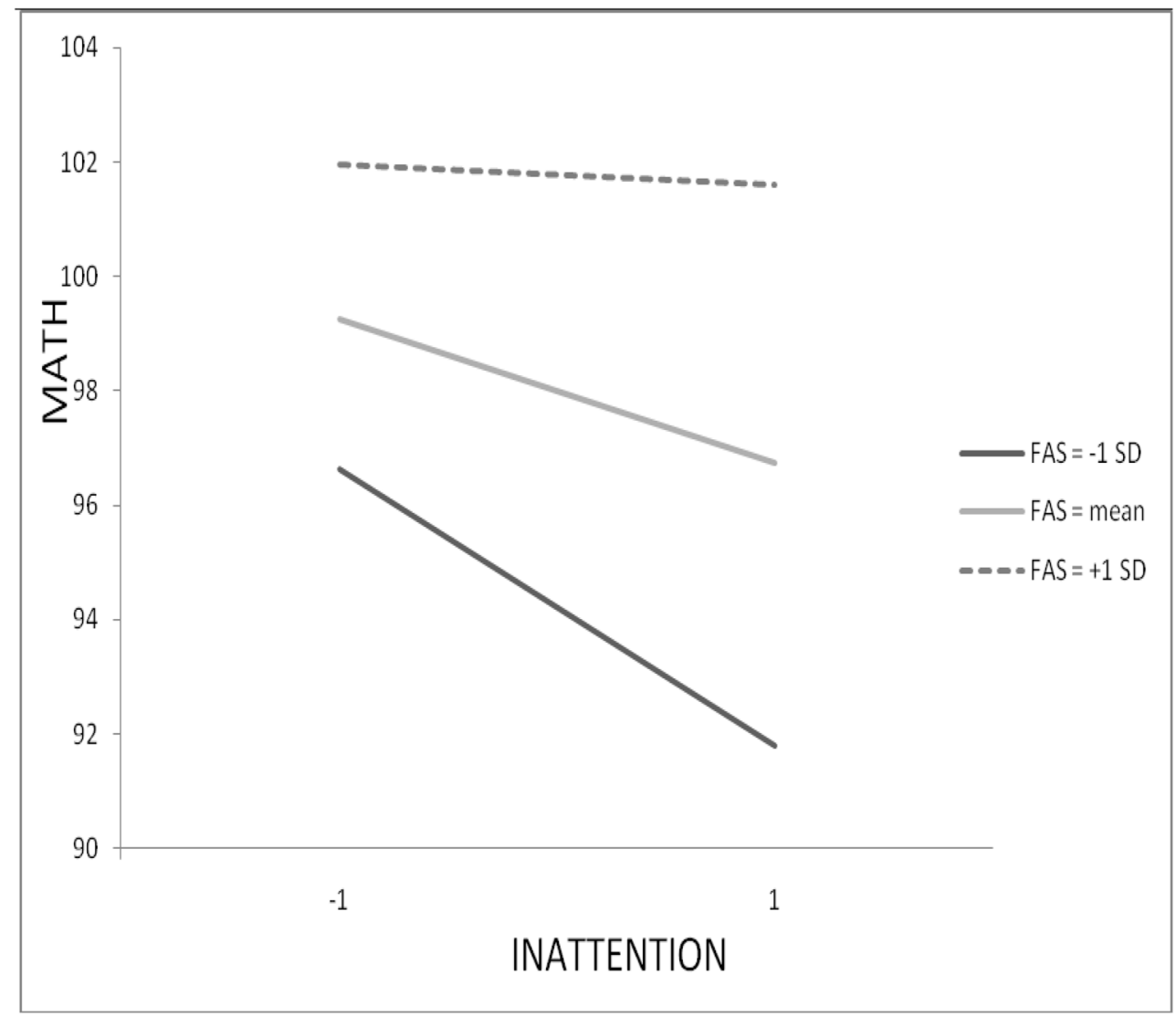

Figure 1.

Interaction between attention problems (Conners inattention z-scores) and Feelings About School (FAS) in predicting mathematics development (Woodcock-Johnson standardized scores). 


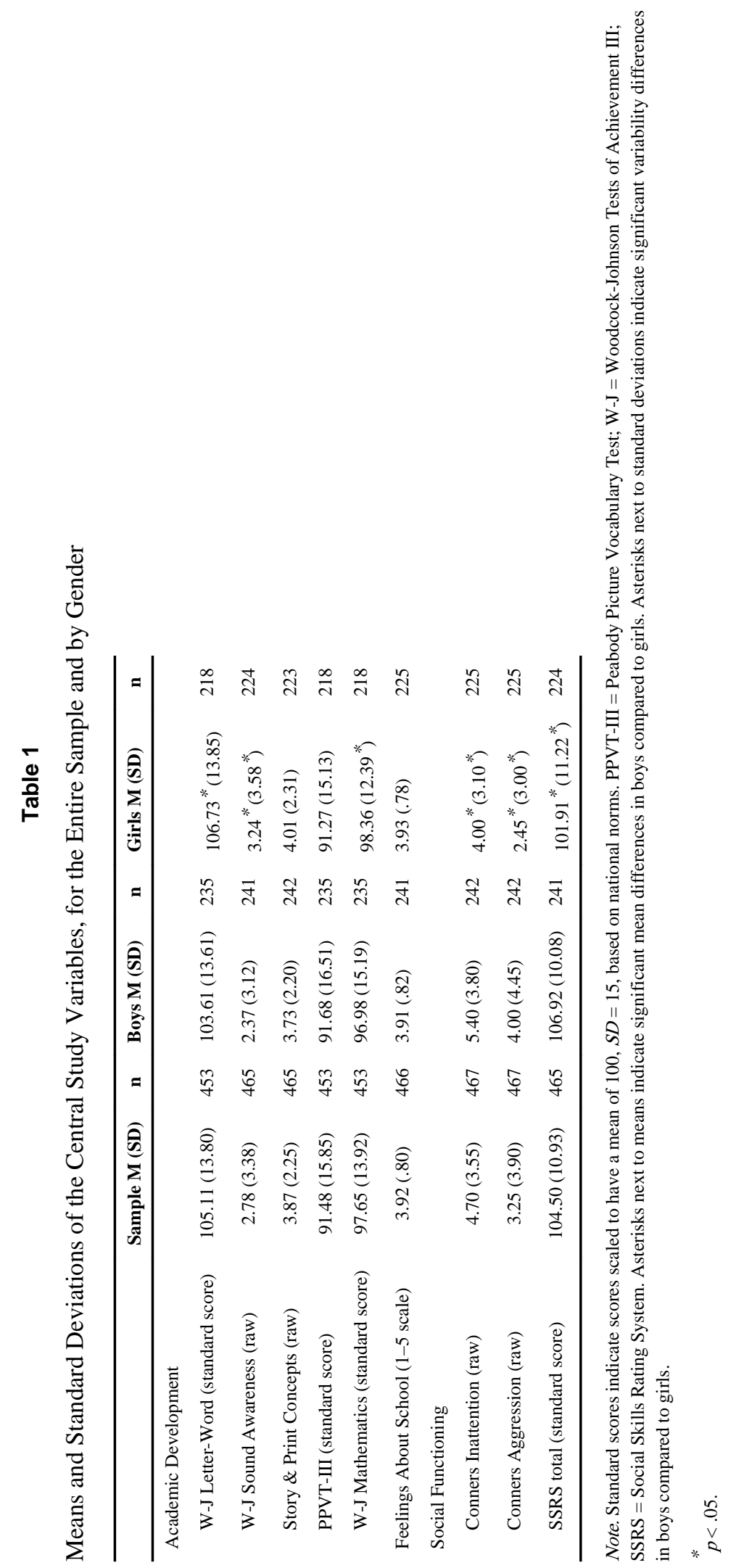

Early Child Res Q. Author manuscript; available in PMC 2013 January 01. 


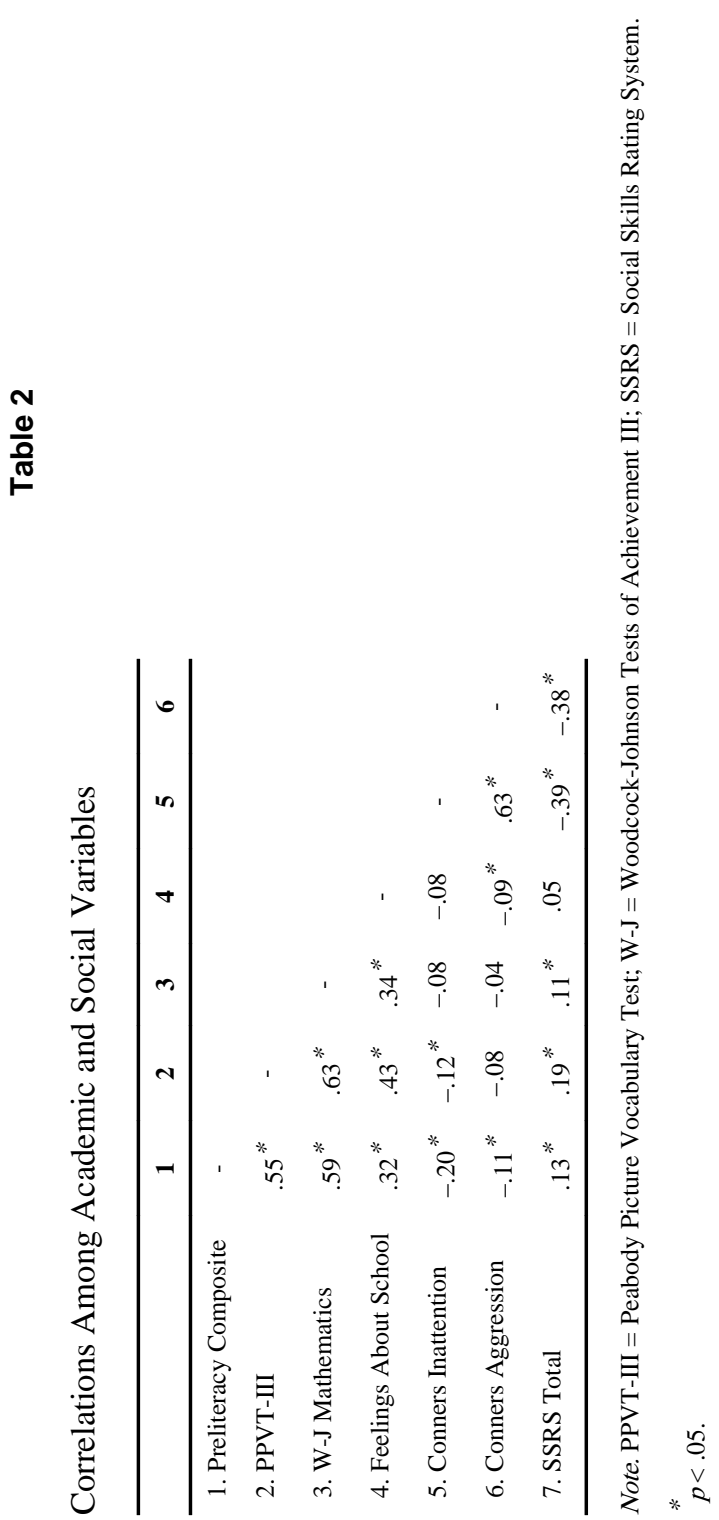

Early Child Res Q. Author manuscript; available in PMC 2013 January 01. 


\section{Table 3}

Predicting Academic Development from Inattention, Aggression, and Social Skills. Standard Errors are in Parentheses.

\begin{tabular}{|c|c|c|c|}
\hline Outcome Variable & Preliteracy & PPVT-III & W-J Mathematics \\
\hline \multicolumn{4}{|c|}{ Fixed Effects } \\
\hline \multicolumn{4}{|l|}{ Predictor } \\
\hline Intercept $\left(\gamma_{00}\right)$ & $.20(.09)^{*}$ & $.03(.08)$ & $.10(.08)$ \\
\hline $\operatorname{Gender}\left(\gamma_{10}\right)$ & $-.37(.10)^{*}$ & $-.09(.09)$ & $-.23(.10)^{*}$ \\
\hline Inattention $\left(\gamma_{20}\right)$ & $-.17(.06)^{*}$ & $-.10(.05)^{*}$ & $-.06(.07)$ \\
\hline Aggression $\left(\gamma_{30}\right)$ & $.07(.05)$ & $.05(.05)$ & $.06(.06)$ \\
\hline $\operatorname{SSRS}\left(\gamma_{40}\right)$ & $.20(.07)^{*}$ & $.19(.05)^{*}$ & $.18(.06)^{*}$ \\
\hline Reduction in Unexplained Variance & .13 & .06 & .04 \\
\hline \multicolumn{4}{|c|}{ Random Effects } \\
\hline SSRS & .11 & & \\
\hline Between-Class Variability (Intercept) & .16 & .32 & .23 \\
\hline Within-Class Variability & .70 & .63 & .76 \\
\hline
\end{tabular}

Note: Gender was coded as $0=$ female, 1 = male. PPVT-III = Peabody Picture Vocabulary Test; W-J = Woodcock-Johnson Tests of Achievement III; SSRS = Social Skills Rating System. Reduction in unexplained variance refers to the reduction in unexplained level one variance explained by the inclusion of the social functioning predictors, compared to a model that includes only gender.

* $p<.05$. 


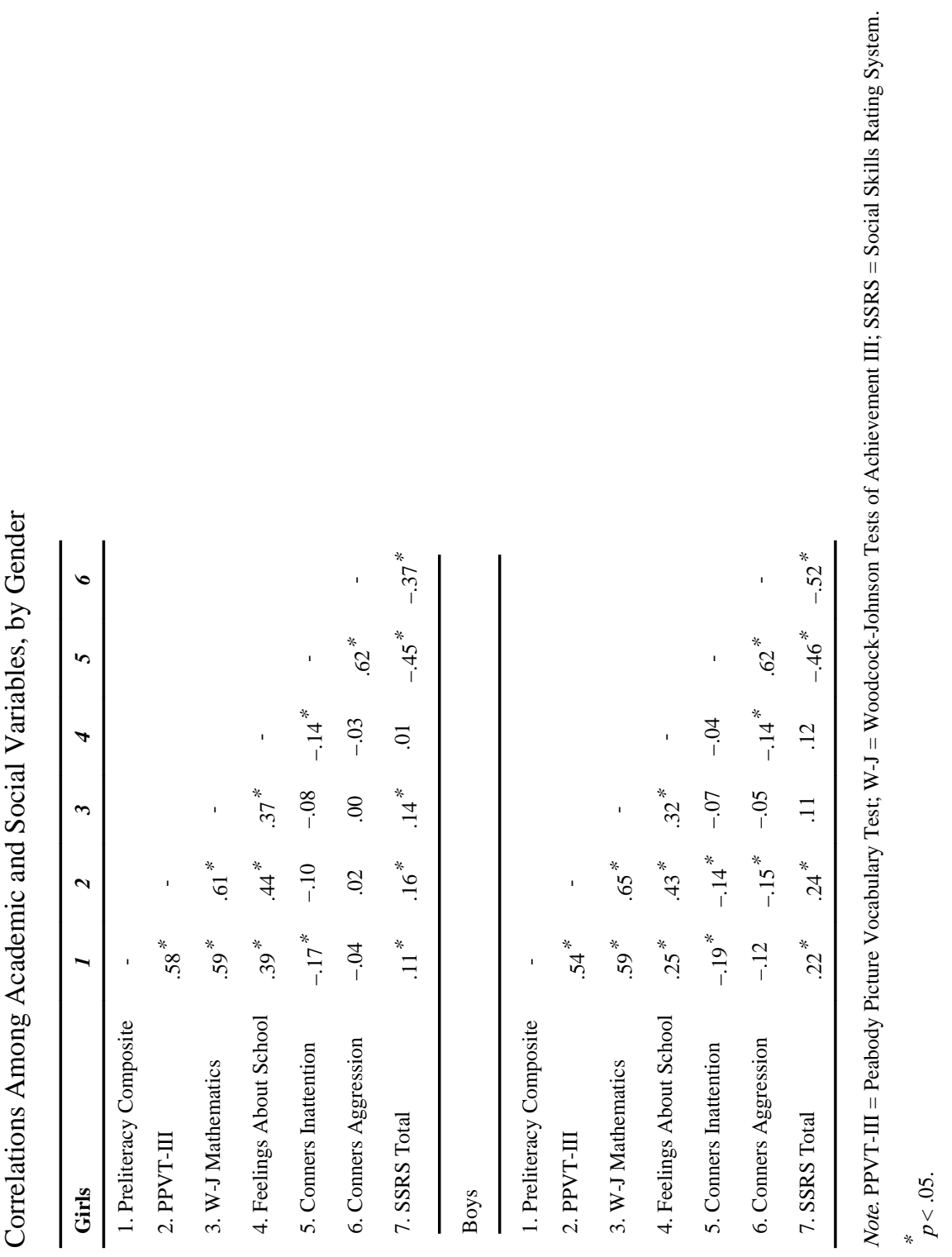


